\title{
Biodiversity gradients in the Alps: the overriding importance of elevation
}

\author{
Fabrizio Sergio $\cdot$ Paolo Pedrini
}

\begin{abstract}
Land abandonment is causing woodland expansion and loss of open habitats in the Alps, coupled with a shift in forestry practices from coppice management to high forest. Despite such rapid large-scale changes, there has been very little investigation of the environmental predictors of biodiversity in the Alpine landscape. We assessed the richness of amphibians, reptiles and breeding birds ( $n=189$ species), used as a surrogate of biodiversity, in 58 quadrats of $100 \mathrm{~km}^{2}$, located within a well surveyed area of the province of Trento (central-eastern Italian Alps). The surrogates were then related to a series of environmental variables by means of stepwise multiple regression. Depending on the surrogate analysed, species richness declined linearly or quadratically with elevation, and increased with habitat heterogeneity and the availability of grassland and arid-rocky habitats. The same results were obtained when incorporating a measure of species threat into the biodiversity estimates. DiVerent surrogates were positively inter-correlated, probably because of a common response to the same factor, namely elevation, which was the only variable to enter all models. Such elevational gradient produced a clear biodiversity peak in low-elevation areas, generating potential conXict between eYcient biodiversity conservation and economic interests linked to human development, a scenario which probably applies to many mountain regions worldwide. The current network of protected areas was quite satisfactory in terms of area covered but biased towards high-elevation areas, of high scenic beauty but relatively low in animal biodiversity value. Low-elevation reserves were small and isolated. Proposed conservation targets include the establishment of corridors increasing the connectivity of low-elevation reserves and the promotion of incentives for the extensive management of grassland, an agro-ecosystem of high historical and biological value.
\end{abstract}

F. Sergio (\&)

Department of Applied Biology, Estación Biológica de Doñana, C.S.I.C., Avda. de Marìa Luisa s/n., Pabellón del Perú, Apdo 1056, Seville, 41013, Spain

e-mail: fsergio@ebd.csic.es

P. Pedrini

Raptor Conservation Research Unit, Trento Museum of Natural Sciences,

Via Calepina 14, Trento, 38100, Italy 
Keywords Alps · Biodiversity $\cdot$ Elevation · Grassland $\cdot$ Habitat heterogeneity · Protected areas $\cdot$ Reserve network $\cdot$ Species richness $\cdot$ Vertebrates

\section{Introduction}

In recent decades, the worldwide rapid loss of biodiversity has promoted new approaches to conservation, with two main emergent trends. Firstly, the traditional focus on single species conservation has been increasingly questioned and replaced with broader biodiversity-driven targets (e.g. Franklin 1993; Tucker and Evans 1997; Entwistle and Dunstone 2000). Secondly, there is increasing consensus that, for biodiversity preservation to be eVective, the establishment of protected areas should be more integrated with the maintenance of hospitable environments within the unprotected matrix of managed landscapes (e.g. Shafer 1994; White et al. 1997; Norris and Pain 2002). This is especially important considering that land-use practices have been identiWed as the single major cause of biodiversity loss in recent years (Soule 1991). The above cited trends have caused a high interest in databases reporting biodiversity estimates over large areas. In this context, atlas data on species distribution have become a valuable tool to derive spatial estimates of species richness (frequently employed as a surrogate of biodiversity, Purvis and Hector 2000) subsequently used for conservation planning (e.g. Boone and Krohn 2000; Wessels et al. 2000; Underhill and Gibbons 2002).

In Europe, the Alps represent a large expanse of natural and semi-natural habitats, which may function as important sources of colonizers for the surrounding intensively cultivated lowlands. Despite such strategic importance and the fact that mountain systems are generally regarded as hotspots of biodiversity (Lomolino 2001; Korner and Spehn 2003), the alpine landscape is currently going through a series of profound changes with unknown biodiversity consequences. Firstly, as in other mountainous areas of Europe, the declining proWtability of agro-pastoral activities is causing widespread land abandonment, with consequent woodland expansion into previously cultivated areas (Cernusca et al. 1999) and negative impacts on species of open habitats (e.g. Laiolo et al. 2004). In particular, woodland extent is increasing through natural regeneration by $0.5-1 \%$ per year, almost exclusively at the expense of abandoned pastures (e.g. PAT 1995; Barbaro et al. 2001; CIPRA 2001; Dirnböck et al. 2003). Such change can be decomposed into two simultaneous processes: (1) at medium-low elevations, land abandonment causes the loss of grassland Welds originally managed for fodder production in association with the once Xourishing livestock industry, an agro-pastoral system which dates back to 6,000 years ago (Lichtenbergen 1994; Dirnböck et al. 2003); (2) at higher elevations, the rapidly declining utilization of alpine pastures for livestock rearing is causing an upward shift of the treeline, originally lowered by human action so as to increase the surface, available for grazing (Dirnböck et al. 2003). Both processes promote a temporary increase in shrub vegetation, which ultimately develops into woodland, leading to long-term loss of alpine grassland and pastures, and declines in landscape heterogeneity. Secondly, the above cited woodland expansion is accompanied by a rapid change in forestry practices. Much of the low-elevation broadleaved woodland, once managed by stool-shoot regeneration (coppice management, Matthews 1989), is being converted to high forest, a process favoured by incentives from local administrations and from the Common Agricultural Policy of the European Union (e.g. IPLA 2000). Such radical, large-scale changes impose an urgent need for investigations of their potential biodiversity impact. To date, there has been few comprehensive investigations of the potential landscape-level determinants of biodiversity in the Alpine 
chain, most of the studies focusing on "restricted" groups of species in speciWc components of the landscape (e.g. birds in grassland habitats, Laiolo et al. 2004).

Here, we: (1) assess the richness of terrestrial vertebrate species in an area of the centraleastern Italian Alps; (2) investigate the potential environmental predictors of biodiversity level; (3) examine the inter-correlation among diVerent biodiversity estimates; (4) assess the potential biodiversity impact of the ongoing landscape changes; (5) identify hotspots of vertebrate diversity and compare them with the location of the local reserve network; and (6) propose conservation guidelines aimed at the long-term preservation of biodiversity in the modern alpine landscape.

\section{Methods}

\section{Study area}

Vertebrate species were surveyed in a $6,300 \mathrm{~km}^{2}$ plot coinciding with the administrative province of Trento, located in the central-eastern Italian Alps ( $45^{\circ} \mathrm{N}, 11^{\circ} \mathrm{E}$, Fig. 1). Elevation of the study area ranged from 65 to $3764 \mathrm{~m}$ a.s.l. Thirty-one percent of the land lay below 1,000 m, twenty-eight percent at an elevation between 1,000 and 1,500 m, 22\% between 1,500 and $2,000 \mathrm{~m}, 13 \%$ between 2,000 and $2,500 \mathrm{~m}$, and $6 \%$ at an elevation $>2,500 \mathrm{~m}$. The natural tree line is at 1,800-1,900 m, but has often been lowered by human activities and sheep grazing. The landscape is characterized by intensively cultivated valley Xoors, mountain slopes covered by forests interspersed with sparse pastures and vineyards at lower elevation, by managed grassland at middle elevation, and by montane grassland, rocky outcrops and permanently snow-covered ground above the tree line. In particular, $52 \%$ of the area was covered by woodland, $18 \%$ by montane grassland and pastures, $6 \%$ by

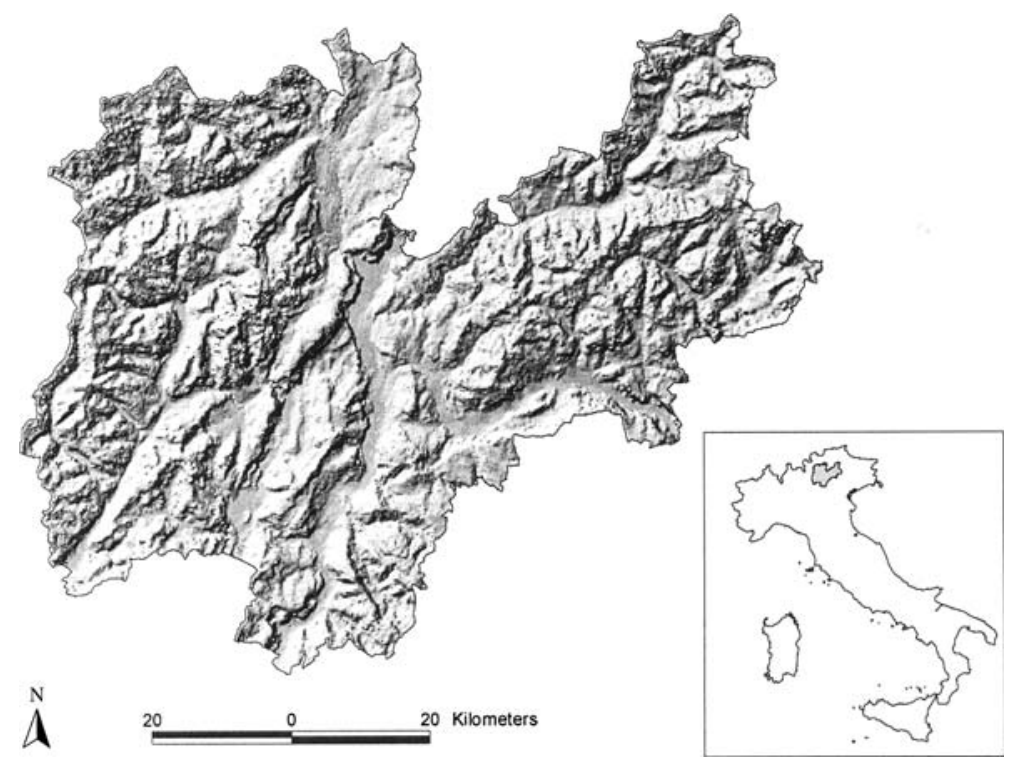

Fig. 1 Relief map of the Administrative Province of Trento. The inset shows the location of the study area in the Italian peninsula 
agricultural crops (mainly vineyards and apple groves) and 3\% by human development (GIS analysis on CEC 1993). Forest composition varied from deciduous to coniferous depending on elevation, slope orientation, and local microclimate. With increasing elevation, woodland tended to be dominated respectively by Quercus pubescens, Quercus-TiliaAcer spp., Fagus-Abies spp., Picea excelsa and Larix decidua-Pinus cembra (PAT 1995). Eighty-two percent of the woodland area was managed for wood production; $73 \%$ of this woodland was managed as high forest and $27 \%$ as coppice (PAT 1995). The network of protected areas is composed of three large parks (Stelvio National Park, Adamello-Brenta Regional Park and Paneveggio-Pale di San Martino Natural Park) and by 65 smaller reserves (“biotopi provinciali”, PAT 1997) (Fig. 3).

\section{Distributional data}

The distribution of terrestrial vertebrate species has been recorded in the study area since 1987, as part of diVerent atlas projects (Caldonazzi et al. 2002; Pedrini et al. 2005), and expressed as the presence-absence of each species in the $10 \mathrm{~km} £ 10 \mathrm{~km}$ quadrats of the national 1:25000 cartography. Intensive Weld surveys were conducted year-round between 1987 and 1996. The data collected in this period showed that species richness increased linearly with sampling eVort, reaching a plateau above 20-25 visits per quadrat. Therefore, between 1996 and 2001, under-sampled quadrats were surveyed until all quadrats had received a minimum of 25 visits. Further details on Weld procedures can be found in Caldonazzi et al. (2002) and Pedrini et al. (2005). For the purpose of this study, we only included in the analyses the quadrats which were included for, $85 \%$ of their surface in the study area ( $n=58$ quadrats), so as to avoid the potential sampling biases associated with area-eVects (Gaston 1996a). For these 58 quadrats, none of the biodiversity estimates was signiWcantly related to the percentage of each quadrat included in the Trento administrative province $(r-0.16, P, 0.24)$.

Statistical and GIS analyses

To investigate the potential eVect of environmental factors on biodiversity, for each quadrat we: (1) calculated the richness of amphibian, reptile and avian species and their cumulated richness (hereafter "vertebrate richness"), and used them as surrogate measures of biodiversity (Table 1); (2) measured the environmental variables reported in Table 1 by accessing GIS land-use maps (CEC 1993; Servizio Foreste 1999) or by digitising 1 m-resolution, aerial colour-photographs (courtesy of Provincia Autonoma di Trento, "Permit IGM n.278 of 30 June 2000”); and (3) employed stepwise multiple regression with a generalised linear model procedure (GLM, Crawley 1993) to relate the biodiversity estimates to the environmental variables of Table 1 . Because high species richness does not necessarily equate to high conservation priority or level of threat (Gaston 1996b), we also calculated for each quadrat the richness of bird species classiWed as vulnerable by Tucker and Heath (1994) (i.e. cumulative richness of species classiWed as SPEC 1, 2, and 3; Table 1), and employed it as a dependent variable in an additional multiple regression. No similar analysis was conducted for amphibians and reptiles because the vulnerability status of such species is less known.

In all regressions, we added to the set of explanatory variables a quadratic term for elevation (calculated on the untransformed variable), because species richness was shown to peak at intermediate elevations in some previous studies (Rahbek 1997; Brown 2001). No direct estimates of climate could be included among the explanatory variables because of a 

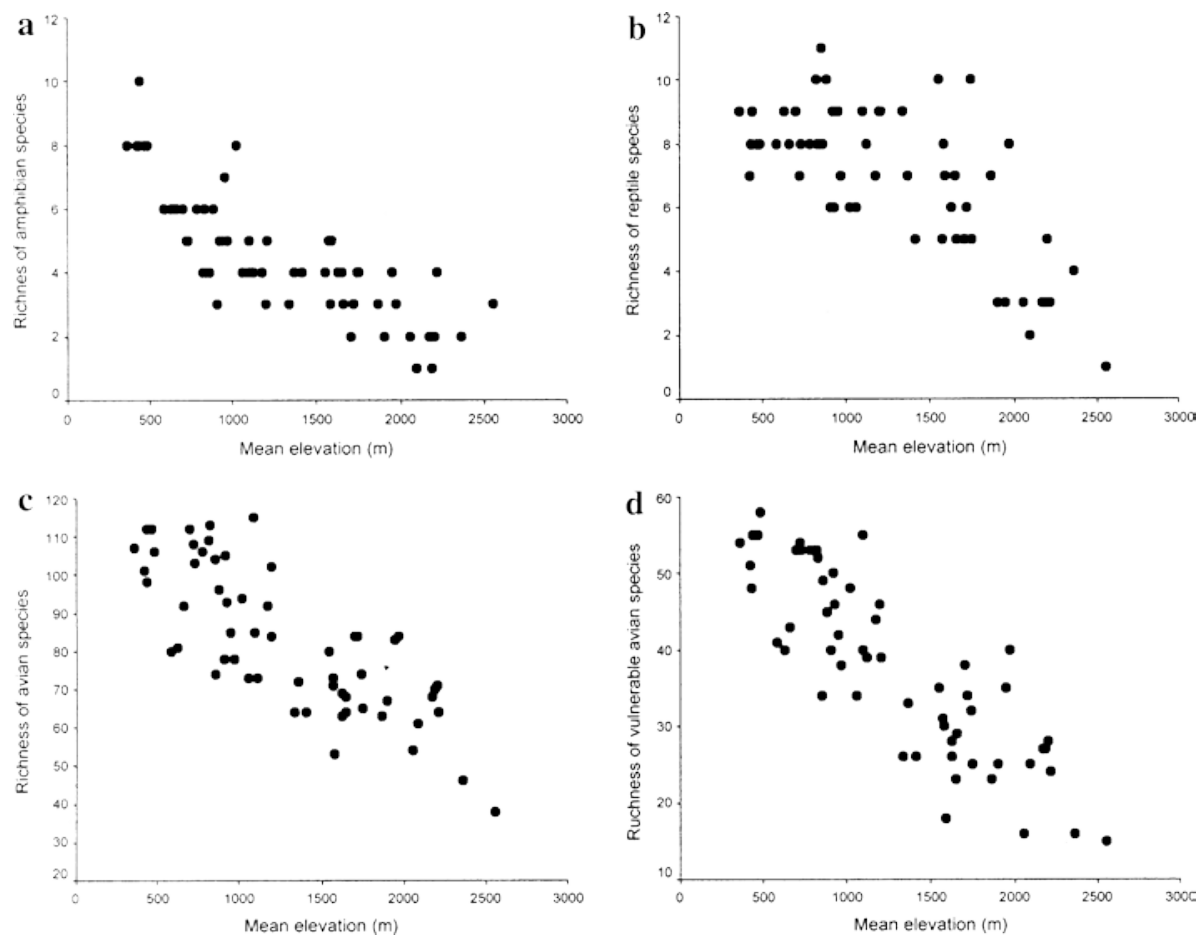

Fig. 2 Elevational decline in species richness for amphibians (a), reptiles (b), birds (c) and vulnerable birds (d)

low number of weather-recording stations with long-enough time-series, However, we assigned each quadrat to a climate-category reXecting the climatic zonation proposed by Odasso (2002) on the basis of soil characteristics and phytosociological community type (Table 1). Furthermore, climate can be adequately estimated through topographical surrogates (e.g. elevation) when: (1) the extent of the study area is relatively small; (2) climate remains relatively constant over the study area; and (3) the lapse rate of temperature with increasing elevation is constant through the study plot (Gandolfo and Sulli 1993; Austin 2002). The three conditions apply to this study.

All multiple regressions (GLMs with Poisson errors and a logarithmic link function) were built by a backward stepwise procedure following Crawley (1993): all explanatory variables were Wtted to the model, extracted one at a time from such maximal model and the associated change in model deviance assessed by a $z^{2}$, test. Overdispersion was checked following Crawley (1993). To reduce collinearity and the number of variables presented to the multivariate models, we employed a modiWcation of the method of variable reduction proposed by Green (1979) and commonly employed in habitat selection studies (e.g. Austin et al. 1996; Sergio and Bogliani 2000; Sergio et al. 2004 and references therein). In this method, pairs of strongly intercorrelated, explanatory variables $(r>0.6)$ are considered as estimates of one underlying factor. Only one of the two is retained for analysis, usually the one considered as more biologically relevant in terms of the investigated relationship. Of the remaining variables, only those that were signiWcantly related to the dependent variable in univariate correlations were retained as explanatory variables.

The relationship among diVerent biodiversity surrogates was assessed by means of univariate correlations (Sokal and Rohlf 1981). To examine whether the current network of 
Table 1 Biodiversity estimates and environmental variables measured at 58 quadrats of $100 \mathrm{~km}^{2}$ (Trento region, central-eastern Italian Alps)

\begin{tabular}{|c|c|}
\hline Variable & Description \\
\hline \multicolumn{2}{|l|}{ Biodiversity estimates } \\
\hline Richness of amphibians & Number of amphibian species recorded as present in the quadrat \\
\hline Richness of reptiles & Number of reptile species recorded as present in the quadrat \\
\hline Richness of birds & Number of bird species recorded as present in the quadrat \\
\hline Richness of vertebrates & Cumulative number of amphibian, reptile and bird species in the quadrat \\
\hline Richness of SPEC 1-4 & Number of vulnerable abird species recorded as present in the quadrat \\
\hline \multicolumn{2}{|l|}{ Environmental variables } \\
\hline Mean elevation (m) & Mean elevation within the quadrat ${ }^{\mathrm{b}}$ \\
\hline Range of elevation (m) & Range of elevation within the quadrat ${ }^{\mathrm{b}}$ \\
\hline Mean slope & Mean slope angle within the quadrat ${ }^{\mathrm{b}}$ \\
\hline Mean ruggedness index & $\begin{array}{l}\text { Mean of the ruggedness indices }{ }^{\mathrm{c}} \text { of each of all the } 1-\mathrm{km}^{2} \\
\text { quadrats included within the } 100-\mathrm{km}^{2} \text { quadrat }\end{array}$ \\
\hline \% urban & $\%$ extent of urban areas ${ }^{\mathrm{d}}$ \\
\hline$\%$ grassland & $\%$ extent of managed grassland ${ }^{\mathrm{d}}$ \\
\hline \% alpine pastures & $\%$ extent of alpine grassland above the tree line ${ }^{\mathrm{d}}$ \\
\hline \% vineyards & $\%$ extent of vineyards ${ }^{\mathrm{d}}$ \\
\hline$\%$ apple groves & $\%$ extent of apple groves ${ }^{\mathrm{d}}$ \\
\hline$\%$ farmland & $\%$ extent of intensive farmland (excluding vineyards and apple groves) ${ }^{\mathrm{d}}$ \\
\hline$\%$ arid & $\%$ extent of rocky outcrops and xerophytic vegetation ${ }^{\mathrm{d}}$ \\
\hline$\%$ shrubs & $\%$ extent of shrubs ${ }^{\mathrm{d}}$ \\
\hline \% shrubs in evolution & $\%$ extent of shrubs evolving into woodland vegetation after land abandonment ${ }^{\mathrm{d}}$ \\
\hline \% broadleaved forest & $\%$ extent of broadleaved forests ${ }^{\mathrm{d}}$ \\
\hline$\%$ conifer forest & $\%$ extent of conifer forests ${ }^{\mathrm{d}}$ \\
\hline$\%$ mixed forests & $\%$ extent of mixed broadleaved and conifer forests ${ }^{d}$ \\
\hline \% water & $\%$ extent of aquatic habitats ${ }^{\mathrm{d}}$ \\
\hline$\%$ roads & $\%$ extent of the road-network ${ }^{\mathrm{d}, \mathrm{e}}$ \\
\hline$\%$ total grassland & Sum of: \% grassland + \% alpine pastures \\
\hline \% total farmland & Sum of: \% vineyards $+\%$ apple groves $+\%$ farmland \\
\hline$\%$ total shrubs & Sum of: \% shrubs + \% shrubs in evolution \\
\hline \% total woodland & \% extent of woodland ${ }^{\mathrm{d}}$ \\
\hline \% coppice woodland & $\%$ extent of coppice-managed woodland ${ }^{f}$ \\
\hline$\%$ high forest & $\%$ extent of mature forest $\mathrm{f}^{\mathrm{f}}$ \\
\hline River length (km) & Length of rivers ${ }^{f}$ \\
\hline No. of wetlands & Number of wetlands $(<0.5 \mathrm{ha})^{\mathrm{g}}$ \\
\hline Habitat diversity & Shannon index of land-use diversity (Krebs 1998) \\
\hline Phyto-climatic factor & $\begin{array}{l}\text { Dichotomic factor discriminating between warm, } \\
\text { dry sites on carbonatic soils (1) and other areas (2) } \\
\text { (based on the zonation by Odasso 2002) }\end{array}$ \\
\hline
\end{tabular}

\footnotetext{
a Species classiWed as SPEC 1, SPEC 2 or SPEC 3 by Tucker and Heath (1994)

b Calculated from a $10 \mathrm{~m}$-resolution digital elevation model

${ }^{c}$ Number of 10-m contour lines crossed by two N-S and W-E transects of $1 \mathrm{~km}$, crossing in the centre of the $1-\mathrm{km}^{2}$ quadrat

${ }^{d}$ Recorded by accessing GIS land-use maps (CEC 1993) and, when necessary, by digitising 1 m-resolution, aerial colour-photographs

e Assuming a 10-m buVer along all asphalted roads

${ }^{\mathrm{f}}$ Recorded by accessing GIS land-use maps (Servizio Foreste 1999) or by digitising 1 m-resolution, aerial colour-photographs

g Digitised from 1 m-resolution, aerial colour-photographs
} 
protected areas is eYcient at preserving biodiversity, we: (1) deWned as biodiversity hotspots the 12 quadrats in the upper quintile of the values of vertebrate richness (Harcourt 2000) and compared their distribution with the location of the main local reserves; and (2) used univariate correlations to relate the biodiversity surrogates to the percentage of each quadrat which was under some sort of protection. Means are given $\S 1 \mathrm{SE}$, tests are twotailed, and statistical signiWcance was set at a $a-0.05$. Prior to parametric tests, variables were logarithmically, square-root or arcsin square-root transformed as necessary in order to achieve a normal distribution or normalise the standardised residuals or multiple regressions. When multiple tests were performed on the same data set, the sequential Bonferroni correction was used to adjust the signiWcance level (Rice 1989).

\section{Results}

Richness of amphibian, reptile and bird species

Data were available for 13 amphibian species, 12 reptile species and 164 avian species. The richness of amphibian species was only related, linearly, to elevation (Table 2a, Fig. 2a). The richness of reptile species showed a quadratic decline with increasing elevation

Table 2 EVect of environmental variables on the richness of vertebrate species recorded in 58 quadrats of $100 \mathrm{~km}^{2}$ (Trento region, central-eastern Italian Alps)

\begin{tabular}{lllll}
\hline Variable & $\begin{array}{l}\text { Parameter } \\
\text { estimate § SE }\end{array}$ & $z^{2}$ & $P$ & $\begin{array}{l}\text { \% deviance } \\
\text { explained }\end{array}$
\end{tabular}

(a) EVect on: richness of amphibian species ${ }^{\mathrm{a}}$ Mean elevation

Constant

(b) EVect on: richness of reptile species

Mean elevation

Mean elevation $^{2}$

Constant

(c) EVect on: richness of bird species

Mean elevation

Mean elevation ${ }^{2}$

Habitat diversity

Constant

(d) EVect on; richness of vertebrate species ${ }^{b}$

Mean elevation

Mean elevation ${ }^{2}$

$\%$ total grassland ${ }^{\mathrm{c}}$

$\%$ arid $^{\mathrm{d}}$

Constant

\begin{tabular}{|c|c|c|}
\hline ¡ $0.051 \S 0.004$ & 10.31 & $<0.01$ \\
\hline $2.894 \S 0.205$ & - & - \\
\hline $0.003 \S 0.002$ & 1.70 & $>0.05$ \\
\hline ¿ $0.002 \S 0.000$ & 8.10 & $<0.02$ \\
\hline $7.325 \S 1.050$ & - & - \\
\hline i 0.022 § 0.023 & 0.98 & $>0.05$ \\
\hline ¡ 0.015 § 0.001 & 9.10 & $<0.01$ \\
\hline $1.287 \S 0.138$ & 8.88 & $<0.01$ \\
\hline ¡ 52.63 § 57.53 & - & - \\
\hline i 0.011 \$ 0.007 & 1.83 & $>0.05$ \\
\hline ¿ $0.002 \S 0.001$ & 10.71 & $<0.01$ \\
\hline $0.377 \S 0.177$ & 5.84 & $<0.05$ \\
\hline $0.591 \S 0.153$ & 11.21 & $<0.001$ \\
\hline $6.182 \S 0.291$ & - & - \\
\hline ¡ 0.037 \$ 0.032 & 3.78 & $<0.05$ \\
\hline ¡ 0.025 § 0.011 & 6.48 & $<0.05$ \\
\hline $0.882 \S 0.123$ & 7.30 & $<0.02$ \\
\hline $0.812 \S 0.224$ & 8.32 & $<0.001$ \\
\hline $7.311 \S 0.221$ & - & - \\
\hline
\end{tabular}

(e) EVect on: richness of vulnerable bird species Mean elevation

Mean elevation ${ }^{2}$

$\%$ total grassland ${ }^{\mathrm{c}}$

$\%$ arid $^{\mathrm{c}}$

Constant

\footnotetext{
a Variable $\log _{e}$ transformed

b Cumulative richness of amphibians, reptiles and bird species

c Variable arcsin square-root transformed
} 
(Table 2b, Fig. 2b). The richness of bird species declined quadratically with elevation and increased with habitat heterogeneity (Table 2c, Fig. 2c). The richness of all vertebrate species showed a quadratic response to elevation and increased with the availability of grassland and arid-rocky habitats (Table $2 \mathrm{~d}$ ). The same variables entered the model with the richness of vulnerable bird species as the dependent variable (Table 2e, Fig. 2d).

\section{Inter-correlation among biodiversity surrogates}

The inter-correlation among the richness of amphibians, reptiles and birds was positive and signiWcant in all cases $(r, 0.60, n=58, P-0.0001)$. The richness of the three vertebrate classes was also positively correlated with the richness of vulnerable bird species (in all cases $r \rightarrow 0.62, n=58, P-0.0001)$. Finally, the richness of vulnerable bird species was positively correlated with the richness of non-vulnerable bird species $(r=0.85, n=58$, $P<0.00001)$.

\section{Biodiversity hotspots and the protected area network}

All the 12 quadrats identiWed as hotspots were located along the main valley Xoors of the region (Fig. 3), as to be expected on the basis of the results outlined above. Most of the quadrats were poorly protected (Fig. 3). The percentage of each quadrat included in any type of protected area increased with the mean elevation of the quadrat $(r=0.37, n=58$,

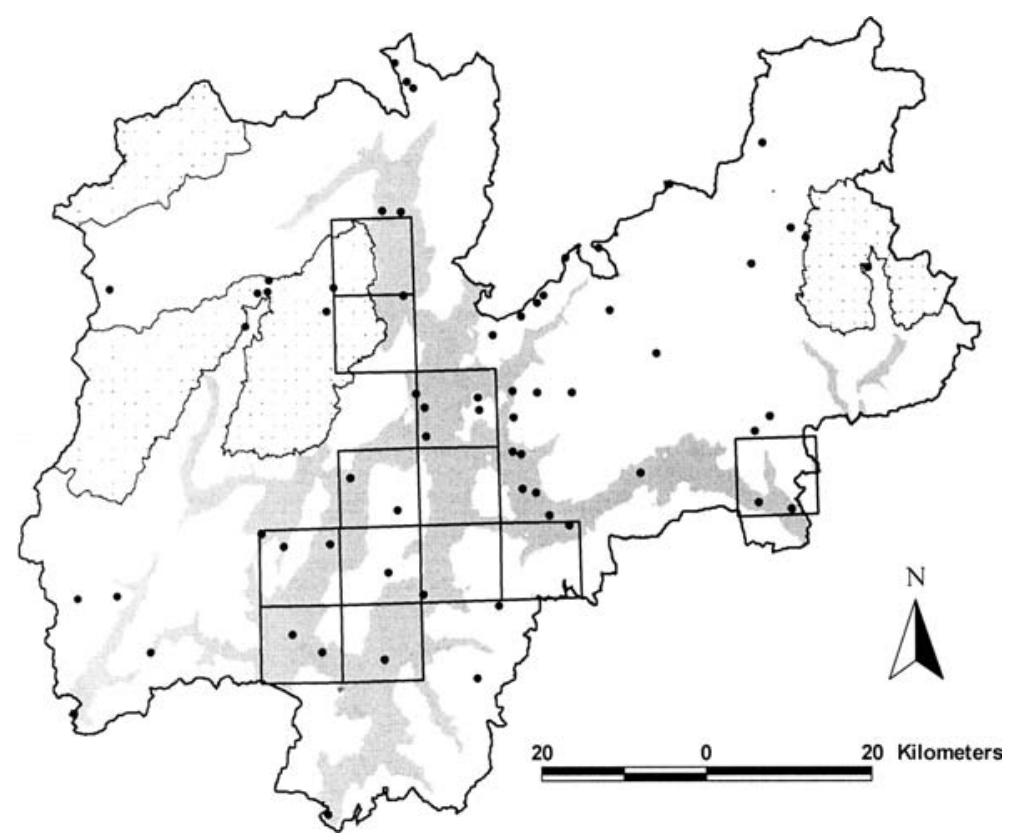

Fig. 3 Biodiversity hotspots and protected areas in the Trento region of the central-eastern Italian Alps. The stippled polygons represent the three large parks of the region (Stelvio, Adamello-Brenta and PaneveggioPale di San Martino), the black points represent the "biotopi provinciali” (smaller reserves). Grey patches depict areas below $800 \mathrm{~m}$ of elevation and the large quadrats are the 12 hotspots identiWed in our dataset on the basis of the cumulative richness of all vertebrate species (see Methods) 
$P=0.03$ ) and was negatively related to all the biodiversity surrogates (all $r-\mathbf{i} 0.18$ ), though only the relationship with reptiles was signiWcant ( $r=$ i $0.33, n=58, P=0.05$ ).

\section{Discussion}

The richness of the vertebrate species employed in this study was related to elevation, habitat heterogeneity and the availability of two land-cover types. At the spatial scale analysed, topography, elevation in particular, was the single most important variable, entering all models and explaining alone a large part of the variation in species richness, as commonly reported in previous studies (review in Gaston and Williams 1996). In agreement with recent reviews (Rahbek 1997; Gaston and Williams 1996; Brown 2001), species richness declined both linearly or quadratically with elevation, depending on the taxa considered. In contrast, we did not observe the biodiversity peak at medium elevations reported by some authors (e.g. Brown 2001), the richness estimates usually declining steadily, though curvilinearly, all along the elevation gradient (Fig. 2). The biodiversity decline with increasing elevation is probably caused by three non-exclusive factors. Firstly, climate becomes progressively colder with increasing elevation, temperature usually declining at a lapse rate of $7^{\circ} \mathrm{C} / \mathrm{km}$ increase in elevation (Wallace and Hobbs 1977; Beninston 1994). The lower temperature at higher elevation, frequently accompanied by higher rainfall and snow cover, results in a progressively more hostile and less energy-rich environment for most species, thus promoting the decline in species richness (e.g. Boone and Krohn 2000). Secondly, the elevational biodiversity decline may be an area-eVect related to the three dimensional surface-decline with increasing elevation typical of mountain systems (Gaston and Williams 1996; Lomolino 2001). The increase in species richness with available area is a long recognized pattern in ecology (species-area curve, review in Rosenzweig 1995). Thirdly, the above cited larger area, more favourable climate and higher available energy at lower elevations may promote high habitat heterogeneity, which is often a direct determinant of species richness (e.g. Owen 1990; Lomolino 2001). In our study, the Wrst explanation (climate-driven elevational decline in species richness) was supported by the fact that ectothermic species seemed to respond solely to elevation while endothermic species responded to elevation as well as to other factors.

Besides the eVect of elevation, bird richness was also positively related to habitat diversity. A higher availability of diVerent habitat types probably implies a higher number of potential niches, ultimately promoting higher species richness (Hutchings et al. 2000; Tilman 2000). A similar relationship has been reported in other previous studies (e.g. Miller 1994; review in Gaston 1996b; Hansen and Rotella 1999) and habitat diversity has even been proposed as a surrogate of biodiversity (reviews in Wessels et al. 1999; Margules and Pressey 2000; Purvis and Hector 2000).

Finally, the richness of all vertebrates and of vulnerable bird species was positively related to the availability of grassland and of arid and rocky habitats. Extensive agro-ecosystems are well known for their biological richness and many species are strictly dependent on such habitats in the Alps (e.g. Pain and Pienkowski 1997; Tucker and Evans 1997; Laiolo et al. 2004). Arid habitats are frequently located in sites with a rugged topography, scarce human access and alteration, and often show particularly warm micro-climates, thus favouring the persistence of many "Mediterranean" species typical of warmer areas (e.g. Marchesi and Sergio 2005). In a way, grassland and arid patches are frequently the main features which stand out of the regional woodland matrix, thus providing an essential contribution to landscape heterogeneity (Forman 1995). 
The positive inter-correlation among the diVerent biodiversity surrogates, including those incorporating a measure of species vulnerability, simpliWes any prioritisation strategy because sites with high species richness for one taxon will also show high richness for other taxa. Such spatial concordance was probably promoted by the common response of all the taxa analysed to the local elevational gradients, as conWrmed by the fact that the inter-correlation among the surrogates disappeared when controlling for the eVect of elevation through a partial correlation analysis (all $r-0.17, P, 0.22$ ). On the contrary, the biodiversity peak at low elevation may generate conXict between the implementation of eYcient conservation and human development, which also peaks at low elevation. In particular, the current reserve network in the Trento region is dominated by three large parks and a series of smaller "biotopi" (Fig. 3). The three parks cover almost exclusively high elevation areas (Fig. 3), while most of the biotopi-reserves coincide with low elevation wetlands, but, despite their obvious value, their size is always too small to allow the persistence of most vertebrate species (mean area $=0.51 \S 0.07 \mathrm{~km}^{2}, n=65$ ). Therefore, the system is characterized by a relatively satisfactory amount of protected land (17\% of the area), but also by a bias towards the preservation of unproductive, high-elevation, biodiversity "poor" sites, a condition which typiWes many developed countries (e.g. Sutherland 1998; Margules and Pressey 2000). Considering that the economic value of the lowlands for agriculture and for urban development makes the planning of large lowland reserves unrealistic, a more rewarding conservation strategy could focus on two targets: (a) utilize the biotopi-reserves as stepping stones and attempt to connect them through corridors; and (b) strive to make the unprotected matrix of the lowlands as hospitable as possible for wildlife. The above scenario is likely to be common to many mountain systems worldwide (see Hansen et al. 1999 for similar conXicts).

As for the habitat changes currently occurring in the alpine landscape, our results suggest that forest expansion per se and the conversion of coppice woodland to high forest may not be necessarily detrimental to biodiversity conservation, unless they imply a large-scale decline in landscape heterogeneity. This is in agreement with the conclusions from previous studies on various species (e.g. Sergio et al. 2003, 2005; Marchesi et al. 2006). On the contrary, the declining availability of grassland could cause long-term biodiversity declines and should be urgently tackled through subsidies for extensive farming, aimed at halting the ongoing land abandonment. In conclusion, our data provide a Wrst, coarse-level assessment of landscape-level gradients in vertebrate species richness. Because regional-levels of biodiversity set the upper limit attainable by local communities (e.g. Cornell and Lawton 1992), this study provides a large-scale framework for more detailed future studies. For example, amphibian richness is probably better modelled at the Wner-scale pond-level, so as to incorporate the eVect of variables such as pond isolation, internal characteristics of the pond (e.g. underwater vegetation, Wsh presence) and hospitability of the habitats surrounding the pond (e.g. Ray et al. 2002; Bosch et al. 2004). Similarly, many avian and reptile species may respond to environmental factors acting at a Wner-grained scale than the one employed in our analyses.

Acknowledgements We thank the numerous people who have taken part to the Weld surveys through the years (list in Caldonazzi et al. 2002) and Pedrini et al. (2005). M. Licantropi, L, Marchesi, V. Penteriani and two anonymous referees gave useful comments on a Wrst draft of the manuscript. This study was included in Project Biodiversità, funded by the Provincia Autonoma di Trento. 


\section{References}

Austin MP (2002) Spatial prediction of species distribution: an interface between ecological theory and statistical modelling. Ecol Model 157:101-118

Austin GE, Thomas CJ, Houston DC, Thompson BA (1996) Predicting the spatial distribution of buzzard Buteo buteo nesting areas using a Geographical Information Systemand remote sensing. J Appl Ecol 33:1541-1550

Barbaro L, Dutoit T, Cozic P (2001) A six-year experimental restoration of biodiversity by shrub-clearing and grazing in calcareous grasslands of the French Alps. Biodivers Conserv 10:119-135

Beniston M (ed) (1994) Mountain environments in changing climates. Routledge, London

Boone RB, Krohn WB (2000) Partitioning sources of variation in vertebrate species richness. J Biogeogr 27:457-470

Bosch J, Boyero L, Martìnez-Solano I (2004) Spatial scales for the management of amphibians populations. Biodivers Conserv 13:409-420

Brown JH (2001) Mammals on mountainsides: elevational patterns of diversity. Glob Ecol Biogeogr 10:101109

Caldonazzi M, Pedrini P, Zanghellini S (eds) (2002) Atlante degli anWbi e dei rettili della provincial di Trento (Amphibia, Reptilia), 1987-1996, con aggiornamenti al 2001. Stud Trent Sci Nat Acta Biol 77:1-173

CEC. Commission of the European Communities, Directorate-General-Environment, Nuclear Safety, Civil Protection (1993) CORINE Land cover-guide technique. OYce for oYcial publications of the european communities, Bruxelles

Cernusca A, Tappeiner U, BayWeld N (1999) Land-use changes in European mountain ecosystems. Blackwell Wissenschafts-Verlag, Berlin

CIPRA (2001) Rapporto sullo stato delle Alpi 2: dati, fatti, problemi, proposte. Centro Documentazione Alpina, Torino

Cornell HV, Lawton JH (1992) Species interactions, local and regional processes, and limits to the richness of ecological communities: a theoretical perspective. J Anim Ecol 61:1-12

Crawley MJ (1993) GLIM for ecologists. Blackwell Science, Oxford

Dirnböck T, Dullinger S, Grabherr G (2003) A regional impact assessment of climate and land-use change on alpine vegetation. J Biogeogr 30:401-407

Entwistle A, Dunstone N (eds) (2000) Priorities for the conservation of mammalian diversity: has the Panda had its day? Cambridge University Press, Cambridge

Forman RTT (1995) Land mosaics: the ecology of landscapes and regions. Cambridge University Press, Cambridge

Franklin JF (1993) Preserving biodiversity: species, ecosystems or landscapes? Ecol Appl 3:202-205

Gandolfo C, Sulli M (1993) Studi sul clima del Trentino per ricerche dendroclimatologiche e di ecologia forestale. Provincia Autonoma di Trento, Trento

Gaston KJ (ed) (1996a) Biodiversity: a biology of numbers and diVerence. Blackwell Science, Oxford

Gaston KJ (1996b) Species richness: measure and measurement. In: Gaston KJ (ed) Biodiversity: a biology of numbers and diVerence. Blackwell Science, Oxford, pp 77-113

Gaston KJ, Williams PH (1996) Spatial patterns in taxonomic diversity. In: Gaston KJ (ed) Biodiversity: a biology of numbers and diVerence. Blackwell Science, Oxford, pp 202-229

Green RH (1979) Sampling design and statistical methods for environmental biologists. John Wiley \& Sons, New York

Hansen A, Rotella J 1999 Abiotic factors. In: Hunter ML (ed) Maintaining biodiversity in forest ecosystems. Cambridge University Press, Cambridge, pp 161-209

Hansen AJ, Rotella JJ, Kraska MPV, Brown D (1999) Dynamic habitat and population analysis: an approach to resolve the biodiversity manager's dilemma. Ecol Appl 9:1459-1476

Harcourt AH (2000) Coincidence and mismatch of biodiversity hostspots: a global survey for the order primates. Biol Conserv 93:163-175

Hutchings MJ, John EA, Stewart AJA (2000) The ecological consequences of environmental heterogeneity. Blackwell Science, Oxford

I.P.L.A. (2000) Sweet chestnut coppice. Blu Edizioni, Cuneo

Korner C, Spehn EM (eds) (2003) Mountain biodiversity: a global assessment. CRC Press, Basel

Krebs CJ (1998) Ecological methodology. HarperCollins, New York

Laiolo P, Dondero F, Ciliento E, Rolando A (2004) Consequences of pastoral abandonment for the structure and diversity of the alpine avifauna. J Appl Ecol 41:294-304

Lichtenbergen E (1994) Die Alpen in Europa. Osterreichische Akademie der Wissenschften, VeröV. Komm. Humanökologie 5:53-86 
Lomolino MV (2001) Elevation gradients of species-density: historical and perspective views. Glob Ecol Biogeogr 10:3-13

Marchesi L, Sergio F (2005) Distribution, density, diet and productivity of the Scops Owl Otus scops in the Italian Alps. Ibis 147:176-187

Marchesi L, Sergio F, Pedrini P (2006) Density, nest-site selection, diet and productivity of the Tawny Owl Strix aluco in the Alps: implications of temporal changes in forest dynamics. Bird Study 53:310-318

Margules CR, Pressey RL (2000) Systematic conservation planning. Nature 405:243-253

Matthews JD (1989) Silvicultural systems. Oxford University Press, Oxford

Miller RI (ed) (1994) Mapping the diversity of nature. Chapman \& Hall, London

Norris K, Pain DJ (eds) (2002) Conserving bird biodiversity: general principles and their application. Cambridge University Press, Cambridge

Odasso M (2002) I tipi forestali del Trentino: catalogo, guida al riconoscimento, localizzazione e caratteristiche ecologico-vegetazionali. Centro di Ecologia Alpina, Trento

Owen JG (1990) Patterns of mammalian species richness in relation to temperature, productivity, and variance in elevation. J Mammal 71:1-13

Pain DJ, Pienkowski MW (eds) (1997) Farming and birds in Europe: the Common Agricultural Policy and its implications for bird conservation. Academic Press, London

PAT (1995) Rapporto sullo stato dell’ambiente. Provincia Autonoma di Trento, Trento

PAT (1997) I biotopi tutelati. Provincia Autonoma di Trento, Trento

Pedrini P, Caldonazzi M, Zanghellini S (eds) (2005) Atlante degli Uccelli nidiWcanti e svernanti in provincia di Trento. Saud Trent Sci Nat Acta Biol 80 (2003) Suppl. 2:1-692

Purvis A, Hector A (2000) Getting the measure of biodiversity. Nature 405:212-219

Rahbek C (1997) The elevational gradient of species richness: a uniform pattern? Ecography 18:200-205

Ray N, Lehman A, Joly P (2002) Modelling spatial distribution of amphibian populations: a GIS approach based on matrix permeability. Biodivers Conserv 11:2143-2165

Rice WR (1989) Analyzing tables of statistical tests. Evolution 43:223-225

Rosenzweig ML (1995) Species diversity in space and time. Cambridge University Press, Cambridge

Sergio F, Bogliani G (2000) Hobby Falco subbuteo nest-site selection and productivity in relation to intensive agriculture and forestry. J Wildl Manage 64:637-646

Sergio F, Pedrini P, Marchesi L (2003) Adaptive selection of foraging and nesting habitat by black kites (Milvus migrans) and its implications for conservation: a multi-scale approach. Biol Conserv 112:351362

Sergio F, Rizzolli F, Marchesi L, Pedrini P (2004) The importance of interspeciWc interactions for breedingsite selection: Peregrine Falcons seek proximity to Raven nests. Ecography 27:818-826

Sergio F, Scandolara C, Marchesi L, Pedrini P, Penteriani V (2005) EVect of agro-forestry and landscape changes on common buzzards (Buteo buteo) in the Alps: implications for conservation. Anim Conserv 8:17-25

Servizio Foreste (1999) Carta Wsionomica della copertura forestale in Trentino. Provincia Autonoma di Trento, Trento

Shafer C (1994) Beyond park boundaries. In: Cook EA, van Lier HN (eds) Landscape planning and ecological networks. Elsevier, Amsterdam, pp 201-223

Sokal RR, Rohlf FJ (1981) Biometry. W.H. Freeman, New York

Soulé ME (1991) Conservation: tactics for constant crisis. Science 253:744-750

Sutherland WJ (ed) 1998. Conservation science and action. Blackwell Science, Oxford

Tilman D (2000) Causes, consequences and ethics of biodiversity. Nature 405:208-211

Tucker GM, Evans MI (1997) Habitats for birds in Europe: a conservation strategy for the wider environment. BirdLife International, Cambridge

Tucker GM, Heath MF (eds) (1994) Birds in Europe: their conservation status. BirdLife International, Cambridge

Underhill L, Gibbons D (2002) Mapping and monitoring bird populations: their conservation uses. In: Norris K, Pain DJ (eds) Conserving bird biodiversity: general principles and their application. Cambridge University Press, Cambridge, pp 34-60

Wallace JM, Hobbs PV (1977) Atmospheric science. Academic Press, New York

Wessels KJ, Freitag S, van Jaarsveld AS (1999) The use of land facets as biodiversity surrogates during reserve selection at a alocal scale. Biol Conserv 89:21-38

Wessels KJ, Reyers B, Van Jaaresveld AS (2000) Incorporating land cover information into regional biodiversity assessments in South Africa. Anim Conserv 3:67-79

White D, Minotti PG, Barczak MJ, Sifneos JC, Freemark KE, Santelmann MV, Steinitz CF, Kiester AR, Preston EM (1997) Assessing risk to biodiversity from future landscape change. Conserv Biol 11:349360 